\title{
The Clinical and Nonclinical Values of Nonexercise Estimation of Cardiovascular Endurance in Young Asymptomatic Individuals
}

\author{
Mahmoud A. Alomari, ${ }^{1}$ Dana M. Shqair,, ${ }^{2}$ Omar F. Khabour, ${ }^{3}$ Khaldoon Alawneh,, 5 \\ Mahmoud I. Nazzal, ${ }^{1,6,7}$ and Esraa F. Keewan ${ }^{8}$ \\ ${ }^{1}$ Division of Physical Therapy, Department of Rehabilitation Sciences, Jordan University of Science and Technology, Irbid 22110, Jordan \\ ${ }^{2}$ Department of Nutrition and Food Technology, Jordan University of Science and Technology, Irbid 22110, Jordan \\ ${ }^{3}$ Department of Medical Laboratory Sciences, Jordan University of Science and Technology, Irbid 22110, Jordan \\ ${ }^{4}$ Department of Internal Medicine, Faculty of Medicine, Jordan University of Science and Technology, Irbid 22110, Jordan \\ ${ }^{5}$ Division of Rheumatology, Department of Medicine, King Abdulla Hospital, Irbid 22110, Jordan \\ ${ }^{6}$ Department of Rehabilitation Medicine, Faculty of Medicine, Jordan University of Science and Technology, Irbid 22110, Jordan \\ ${ }^{7}$ Department of Rehabilitation Medicine, King Abdulla Hospital, Irbid 22110, Jordan \\ ${ }^{8}$ Department of Physiology, Faculty of Medicine, Jordan University of Science and Technology, Irbid 22110, Jordan
}

Correspondence should be addressed to Mahmoud A. Alomari, alomari@just.edu.jo

Received 11 October 2011; Accepted 11 December 2011

Academic Editors: C. L. Athanasuleas and B. Pitt

Copyright (C) 2012 Mahmoud A. Alomari et al. This is an open access article distributed under the Creative Commons Attribution License, which permits unrestricted use, distribution, and reproduction in any medium, provided the original work is properly cited.

\begin{abstract}
Exercise testing is associated with barriers prevent using cardiovascular (CV) endurance (CVE) measure frequently. A recent nonexercise model (NM) is alleged to estimate CVE without exercise. This study examined CVE relationships, using the NM model, with measures of obesity, physical fitness (PF), blood glucose and lipid, and circulation in 188 asymptomatic young (18-40 years) adults. Estimated CVE correlated favorably with measures of PF $(r=0.4-0.5)$ including handgrip strength, distance in 6 munities walking test, and shoulder press, and leg extension strengths, obesity $(r=0.2-0.7)$ including \% body fat, body water content, fat mass, muscle mass, BMI, waist and hip circumferences and waist/hip ratio, and circulation $(r=0.2-0.3)$ including blood pressures, blood flow, vascular resistance, and blood $(r=0.2-0.5)$ profile including glucose, total cholesterol, LDL-C, HDL-C, and triglycerides. Additionally, differences $(P<0.05)$ in examined measures were found between the high, average, and low estimated CVE groups. Obviously the majority of these measures are CV disease risk factors and metabolic syndrome components. These results enhance the NM scientific value, and thus, can be further used in clinical and nonclinical settings.
\end{abstract}

\section{Introduction}

Diseases of the cardiovascular $(\mathrm{CV})$ system are the number 1 cause of mortality and morbidity in the world and will continue to be for years to come [1]. Reduced CV endurance (CVE) increases the risk of hypertension, obesity, diabetes, and coronary, cerebral, and peripheral vascular diseases in a variety of populations [2,3]. Recently, $12.2 \%$ of myocardial [4] and $28.5 \%$ of cerebral [5] infarctions were attributed to lack of physical activities in 2 largescale studies involving 74 countries. Additionally, studies have found that determining CVE can predict all-cause and $\mathrm{CV}$-related mortality and morbidity in children and young and older adults with and without CV diseases (CVD). Therefore, many have recommended to include CVE testing in the screening for CVDs $[6,7]$. However, the risk, time constrains, inconvenience, and cost associated with exercise testing prevent from using the maximal oxygen consumption $\left(\mathrm{VO}_{2} \max \right)$ measure, the direct and golden standard for CVE, frequently $[8,9]$.

The previously developed [10] and recently cross-[11] and criterion- [12] validated nonexercise model (NM) has been found reasonably accurate to estimate CVE [13]. The model is based on the regression of independent and objective variables recognized to be related to CVE and CVD, such as gender, age, body mass index (BMI), resting 
heart rate (HR), and self-reported habitual physical activity (PA) levels. The method is proposed to be a valid and simple measure of CVE that can be used in clinical setting without the difficulties of exercise testing [13]. However the relationships of $\mathrm{NMVO}_{2}$ max with CVD risk factors and metabolic syndrome components have not been examined.

Therefore, the study evaluated the relationships of $\mathrm{NMVO}_{2}$ max with measures of physical fitness (PF), obesity, circulatory, and blood glucose and lipid profile in young asymptomatic individuals. Given previous findings $[2,7,13$, $14]$, these measures are expected to be related to $\mathrm{NMVO}_{2}$ max. Indeed, the majority of these measures are related to CVD and the metabolic syndrome. These relationships are particularly important for future clinical and nonclinical considerations of the model. Especially in the screening for CVDs asymptomatic individuals can benefit from primary prevention programs to avoid or at least delay CVDs [15].

\section{Methodology}

2.1. Participants and Study Design. Asymptomatic apparently healthy males and females between 18 and 40 year old were invited to participate in this cross-sectional study. The exclusion criteria were fasting plasma triglycerides $\geq$ $150 \mathrm{mg} / \mathrm{dL}$; HDL-C < 40/50 mg/dL (men/women); glucose $\geq 110 \mathrm{mg} / \mathrm{dL}$; or $\mathrm{BP} \geq 130 / 85 \mathrm{mmHg}$ [16]. Additionally, smokers and individuals with metabolic and CVDs or taking medications that might affect vascular function, BP, or blood glucose and lipid profile were excluded from the study. After a detailed orientation of the experimental procedures, possible risks, benefits, and requirements, all individuals signed an informed consent approved by the institutional review board.

\subsection{Health-Related Fitness Measures}

2.2.1. Anthropometrics. Body weight (Bweight) in kilograms/the squared height in meters was used to calculate BMI [17]. Additionally, the participants' percent body fat (Fpercent) and body water (Bwater) were measured using bioelectrical impedance (Microlife WS 100, Microlife AG, Heerbrugg, Switzerland). Subsequently fat mass (Fmass) was calculated as Fpercent $*$ Bweight whereas muscle mass (Mmass) was calculated as the difference between Bweight and Fmass [17]. The ratio of the waist and hip (WHR) was calculated after determining the waist (WC) and hip (HC) circumferences at the umbilicus height and at the greatest circumference in the pelvic bone, respectively [17].

2.2.2. Physical Fitness. Handgrip (HGS), shoulders press (Shpress) and leg extension (Lgext) strengths as well as the 6minute walk test (6 MWD) were used as measures of physical fitness. The average HGS was calculated after 3 all-out griping trials in the dominant hand using a dynamometer [17]. Each participant walked as fast as possible to examine the maximum distance achieved in 6 minutes (6 MWD) [18]. Shoulder press (Shpress) and leg extension (Lgext) machines were used to determine upper and lower body strengths, respectively. The weight-lifted $2-20$ repetitions were applied to the "one repetition maximum (1-RM)" equation to determine maximal strength. The $1-\mathrm{RM}$ equation $=\mathrm{kg}$ at \#RM 2 - 20/[1.00 - (\#RM * 0.02)], given that \#RM = number of repetitions performed, $1.00=100 \%$ as a decimal, and $0.02=2 \%$ as a decimal. The $1-\mathrm{RM}$ was then multiplied by $70 \%$ to determine Shpress, and Lgext endurances [17].

\subsection{Circulatory Measures}

2.3.1. Blood Pressure. Automated noninvasive auscultatory (Omron HEM-907XL, Omron Healthcare, Inc, Bannockburn, Illinois) BP measurements for the systolic (SBP) and diastolic (DBP) pressures and HR were obtained from the participants after 20 minutes of supine resting. Pulse pressure (PP) was calculated as SBP-DBP whereas mean arterial pressure (MAP) was calculated as DBP $+(1 / 3 * \mathrm{PP})[17]$.

2.3.2. Vascular Function. Vascular function measurements were explained previously in details [19]; however they will be briefly described. The participants' blood flows $(\mathrm{BF})$ at rest $(\mathrm{RBF})$ and after reactive hyperemia (RHBF) were measured in the dominant forearm with strain-gauge plethysmography, from a supine position after 20 minutes resting. Forearm RBF was measured immediately after releasing a pressure of $7 \mathrm{mmHg}$ below DBP applied with another tourniquet placed above the elbow. The RHBF was obtained after occluding the upper arm arterial circulation for 5 minutes. The calculations, for RBF and RHBF, were made from the slop drawn at the 1st 2-3 beats of the volume graph. Subsequently, vascular resistance $(\mathrm{Vr})$ at rest $(\mathrm{RVr})$ and after 5 minutes of upper arm arterial occlusion (RHVr) was calculated as MAP/Vr [19].

2.4. Glucose and Lipid Profile Measures. Blood samples after overnight fasting were drawn from each participant by venipuncture into $5 \mathrm{~mL}$ plain tubes for serum lipids and triglycerides determination and into $4 \mathrm{~mL}$ EDTA containing tubes for blood glucose and lipid profile (cholesterol, HDL-C, LDL-C, HDL/LDL, triglyceride) measurements. The serum was separated from blood cells by centrifugation at $2000 \times \mathrm{g}$ for $10 \mathrm{~min}$. All biochemical parameters were assayed in the laboratory of King Abdulla University Hospital, Irbid, Jordan using Roche Chemistry Analyzer and reagents (Roche Diagnostics, Indianapolis, IN, USA). For all assays, the intraassay coefficient of variation was less than $2.6 \%$ [20].

2.5. Physical Activity Level. The short-form Arabic version of the international PA questionnaire (IPAQ) was used to obtain the level of PA [21]. The subjects were classified into low, medium, and high PA levels, according to total PA participation. The classifications were according to $<600$, 601-1500 and >1501, and assigned the values 1, 2, and 3, respectively [21]. These values were then used in the non exercise regression equation to estimate $\mathrm{VO}_{2} \max [10]$.

2.6. Estimation of $\mathrm{VO}_{2}$ Max Using the Nonexercise Regression Model. The regression model, originally developed by 
TABle 1: Participant characteristics $(n=188)$.

\begin{tabular}{lcc}
\hline Variable & Mean \pm SD & Range \\
\hline Age (years) & $24.04 \pm 5.3$ & $18-40$ \\
Weight $(\mathrm{kg})$ & $69.7 \pm 15.8$ & $41-119$ \\
Height $(\mathrm{cm})$ & $168.6 \pm 9.5$ & $146-189$ \\
Body mass index & $24.35 \pm 4.3$ & $16.5-37.3$ \\
Estimated $\mathrm{VO}_{2}\left(\mathrm{~mL} \cdot \mathrm{kg}^{-1} \cdot \mathrm{min}^{-1}\right)$ & $46.4 \pm 6.7$ & $23.1-58.9$ \\
\hline
\end{tabular}

TABLE 2: Estimated maximum $\mathrm{VO}_{2}$ relationship with physical fitness measures.

\begin{tabular}{lccc}
\hline & Physical fitness measures & $r$ value & $P$ value \\
\hline \multirow{3}{*}{ Estimated } & Handgrip strength & 0.5 & 0.000 \\
$\mathrm{VO}_{2}$ max & 6 MWD & 0.5 & 0.000 \\
& Leg extension 1RM & 0.4 & 0.000 \\
& Shoulder press 1RM & 0.5 & 0.000 \\
\hline
\end{tabular}

Jackson, was used to estimate CVE according to $\mathrm{VO}_{2}$ max $=[$ Gender $($ female $=0 ;$ male $=1) * 2.77]-[$ Age $* 0.10]$ - [BMI * 0.17] - [resting HR * 0.03] + [PA level $* 1]$ +18.07 . Subsequently, the participants were classified into poor, average, and high level of CVE [10].

2.7. Statistical Analysis. Pearson's correlations were used to examine the relationships of $\mathrm{NMVO}_{2}$ max with $\mathrm{PF}$, circulatory, and blood glucose and lipid profile measures. Additionally, after dividing the participants into poor, average, and high CVE groups, 1-way ANOVA tests were used to examine the difference between the 3 groups in these measures.

\section{Results}

3.1. Participants. As in Table 1, 188 Arab individuals participated in the study including 90 males and 98 females with estimated $\mathrm{VO}_{2}$ max of $51.15 \pm 4.6$ and $42.0 \pm$ $5.0 \mathrm{~mL} \cdot \mathrm{kg}^{-1} \cdot \mathrm{min}^{-1}$, respectively. The distribution of poor, average, and high estimated $\mathrm{VO}_{2}$ max groups was $6.4(n=$ 12), 55.8 ( $n=105)$, and $37.7 \%(n=71)$, respectively, with estimated $\mathrm{VO}_{2} \max 34.1 \pm 7.1,43.9 \pm 4.1$, and $53.1 \pm$ $4.5 \mathrm{~mL} \cdot \mathrm{kg}^{-1} \cdot \mathrm{min}^{-1}$, respectively. The number of males and females in the poor, average, and high estimated $\mathrm{VO}_{2} \max$ groups was 1, 36, and 53, and 11,69, and 18, respectively.

\subsection{Estimated $\mathrm{VO}_{2}$ Max Relationships with Health-Related} Fitness Measures. Tables 2 and 3 show that estimated $\mathrm{VO}_{2}$ max correlated with HGS, $6 \mathrm{MWD}$, and Shpress and Lgext strength and endurance, as well as with Bweight, Fpercent, Fmass, Bwater, and WHR ( $r$ value range: $0.2-0.7)$. Differences ( $P$ value range: $0.05-0.000)$ between the 3 groups in HGS, 6MWD, Spress and Lgext are shown in Table 4. Similarly, Table 4 demonstrates differences $(P$ value range: 0.02-0.000) between the 3 groups in Bweight, BMI, Fpercent, Fmass, Mmass, Bwater, WC, and HC.

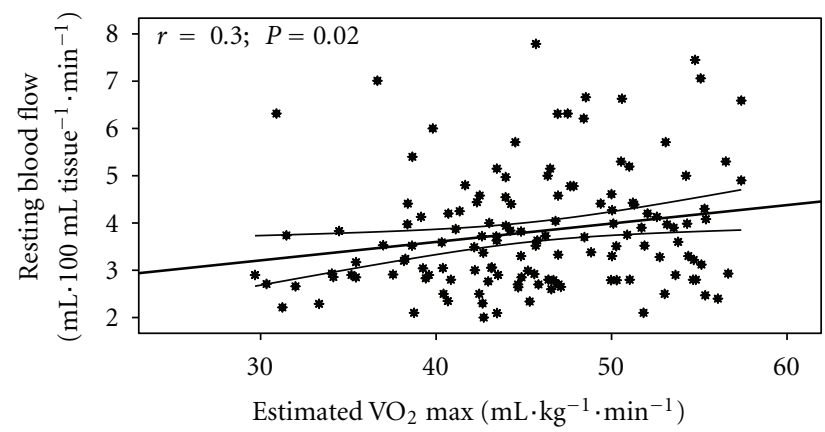

(a)

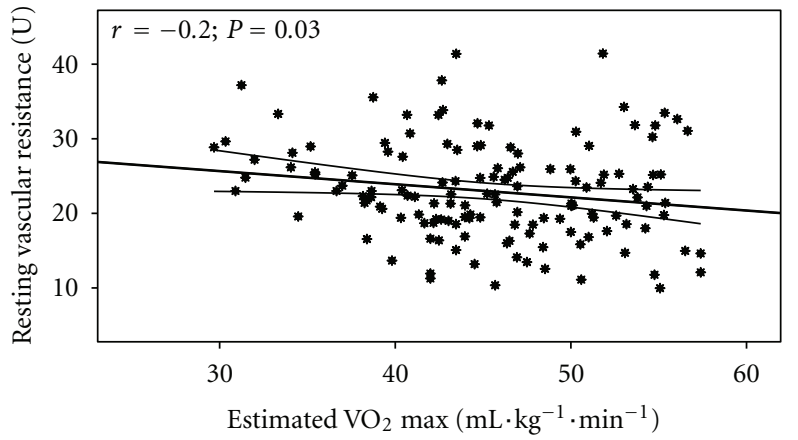

(b)

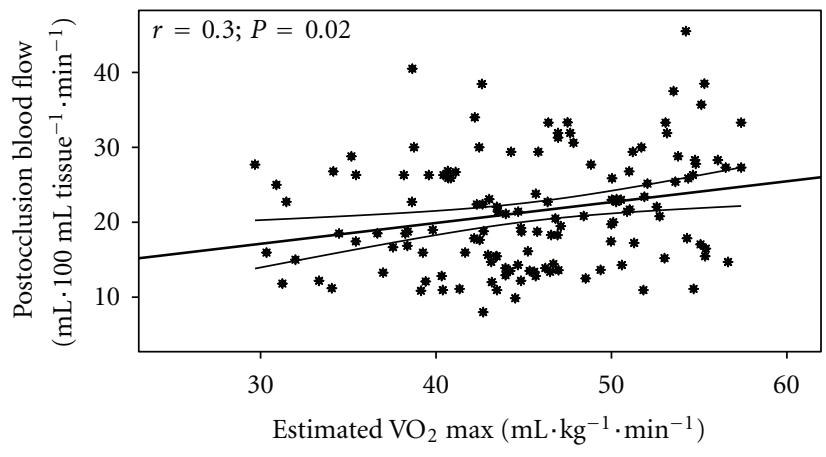

(c)

FIGURE 1: Estimated $\mathrm{VO}_{2}$ relationship with resting blood flow (a) $(r=0.3 ; P=0.02)$, resting vascular resistance $(\mathrm{b})(r=-0.2 ; P=$ $0.03)$, and postocclusion blood flow (c) $(r=0.3 ; P=0.02)$.

3.3. Estimated $\mathrm{VO}_{2}$ Max Relationships with Circulatory Measures. Estimated CVE relationships with $\mathrm{BF}$ and $\mathrm{Vr}$ are shown in Figure 1 and with DBP and MAP are shown in Figures 2 and 3. Additionally, differences between the 3 groups in $\operatorname{RVr}(P=0.05)$ and $\operatorname{RHBF}(P=0.000)$ are shown in Figures 4 and 5.

3.4. Estimated $\mathrm{VO}_{2}$ Max Relationships with Blood Glucose and Lipid Profile. Estimated $\mathrm{VO}_{2}$ correlated favorably with blood glucose, cholesterol, HDL-C, LDL-C, HDL/LDL, and triglyceride in the males and females (Table 5) separately and with cholesterol (Figure 6(a)) and LDL-C (Figure 6(b)) for the males and females combined. Figure 7 revealed that blood glucose, cholesterol, and LDL-C were different $(P<0.05)$ between the 3 groups. Table 6 shows that blood 
TABLE 3: Estimated maximum $\mathrm{VO}_{2}$ relationship with body composition measures in the males and females.

\begin{tabular}{|c|c|c|c|c|}
\hline & Body composition measures & Gender & $r$ value & $P$ value \\
\hline \multirow{7}{*}{$\begin{array}{l}\text { Estimated } \\
\mathrm{VO}_{2} \max \end{array}$} & Weight & $\begin{array}{c}\text { Males } \\
\text { Females }\end{array}$ & $\begin{array}{l}-0.5 \\
-0.6\end{array}$ & $\begin{array}{l}0.000 \\
0.000\end{array}$ \\
\hline & Body fat percent & $\begin{array}{c}\text { Males } \\
\text { Females }\end{array}$ & $\begin{array}{l}-0.6 \\
-0.6\end{array}$ & $\begin{array}{l}0.000 \\
0.000\end{array}$ \\
\hline & Body fat mass & $\begin{array}{c}\text { Males } \\
\text { Females }\end{array}$ & $\begin{array}{l}-0.6 \\
-0.7\end{array}$ & $\begin{array}{l}0.000 \\
0.000\end{array}$ \\
\hline & Body water content & $\begin{array}{c}\text { Males } \\
\text { Females }\end{array}$ & $\begin{array}{l}0.3 \\
0.4\end{array}$ & $\begin{array}{l}0.020 \\
0.006\end{array}$ \\
\hline & Waist circumference & $\begin{array}{c}\text { Males } \\
\text { Females }\end{array}$ & $\begin{array}{l}-0.5 \\
-0.5\end{array}$ & $\begin{array}{l}0.000 \\
0.000\end{array}$ \\
\hline & Hip circumference & $\begin{array}{c}\text { Males } \\
\text { Females }\end{array}$ & $\begin{array}{l}-0.2 \\
-0.6\end{array}$ & $\begin{array}{l}0.030 \\
0.000\end{array}$ \\
\hline & Waist/hip & $\begin{array}{c}\text { Males } \\
\text { Females }\end{array}$ & $\begin{array}{l}-0.5 \\
-0.2 \\
\end{array}$ & $\begin{array}{l}0.000 \\
0.040 \\
\end{array}$ \\
\hline
\end{tabular}

TABle 4: Physical capacity and body composition measures in the high, average, and low estimated $\mathrm{VO}_{2}$ groups.

\begin{tabular}{|c|c|c|c|c|}
\hline \multirow{2}{*}{ Measures } & \multicolumn{3}{|c|}{ Estimated $\mathrm{VO}_{2}$ groups } & \multirow[b]{2}{*}{ ANOVA } \\
\hline & $\operatorname{High}(n=71)$ & Average $(n=105)$ & Low $(n=12)$ & \\
\hline Handgrip strength $(\mathrm{kg})$ & $31.9 \pm 11.1$ & $29.3 \pm 13.2$ & $24.6 \pm 11.1^{* \$}$ & 0.020 \\
\hline Maximal walked distance (m) & $654.9 \pm 92.8$ & $579.0 \pm 82.2^{\$}$ & $517.3 \pm 65.4^{* \$}$ & 0.000 \\
\hline Leg extension 1-RM (kg) & $41.00 \pm 18.1$ & $36.10 \pm 21.0^{\$}$ & $31.40 \pm 10.6^{\$}$ & 0.050 \\
\hline Shoulder press 1-RM (kg) & $41.60 \pm 15.3$ & $34.80 \pm 17.0^{\$}$ & $30.80 \pm 9.2^{\$}$ & 0.040 \\
\hline Weight $(\mathrm{kg})$ & $67.4 \pm 13.0$ & $69.9 \pm 16.6$ & $82.2 \pm 17.6^{* \$}$ & 0.020 \\
\hline Body mass index & $22.2 \pm 3.2$ & $24.5 \pm 4.2^{\$}$ & $30.0 \pm 4.6^{* \$}$ & 0.000 \\
\hline Body fat percent $(\%)$ & $16.7 \pm 5.8$ & $25.2 \pm 6.1^{\$}$ & $32.3 \pm 5.8^{* \$}$ & 0.000 \\
\hline Body fat mass $(\mathrm{kg})$ & $11.4 \pm 4.8$ & $18.0 \pm 7.0^{\$}$ & $27.0 \pm 8.5^{* \$}$ & 0.000 \\
\hline Body muscle mass (kg) & $56.2 \pm 10.7$ & $52.1 \pm 12.0^{\$}$ & $55.3 \pm 11.4$ & 0.040 \\
\hline Water content $(\mathrm{kg})$ & $62.0 \pm 5.6$ & $54.0 \pm 3.4^{\$}$ & $54.7 \pm 3.5^{\$}$ & 0.000 \\
\hline Waist circumference $(\mathrm{cm})$ & $78.8 \pm 10.0$ & $80.8 \pm 13.3$ & $90.7 \pm 15.1^{* \$}$ & 0.009 \\
\hline Hip circumference $(\mathrm{cm})$ & $99.2 \pm 7.5$ & $102 \pm 10.2^{\$}$ & $111.2 \pm 9.8^{* \$}$ & 0.000 \\
\hline Waist/hip & $0.8 \pm 0.07$ & $0.8 \pm 0.09$ & $0.8 \pm 0.1$ & 0.620 \\
\hline
\end{tabular}

Values are in mean \pm SD. ${ }^{*}: P<0.05$ versus the average; $\$: P<0.05$ versus the high group.

TABLE 5: Estimated maximum $\mathrm{VO}_{2}$ relationship with blood glucose and lipid profile in the males and females.

\begin{tabular}{|c|c|c|c|c|c|c|c|}
\hline & & Glucose & Cholesterol & HDL-C & LDL-C & HDL/LDL & Triglyceride \\
\hline \multirow{2}{*}{$\begin{array}{l}\text { Estimated } \\
\mathrm{VO}_{2}\end{array}$} & Males & $-0.04 ; 0.8$ & $-0.4 ; 0.01^{*}$ & $0.3 ; 0.03^{*}$ & $-0.3 ; 0.02^{*}$ & $0.3 ; 0.03^{*}$ & $-0.5 ; 0.002^{*}$ \\
\hline & Females & $-0.4 ; 0.007^{*}$ & $-0.3 ; 0.03^{*}$ & $0.1 ; 0.5$ & $-0.3 ; 0.03^{*}$ & $0.3 ; 0.05^{*}$ & $-0.3 ; 0.03^{*}$ \\
\hline
\end{tabular}

*: significantly correlating with estimated maximal oxygen consumption.

TABLE 6: Blood glucose and lipid profile for the males in the high and average estimated $\mathrm{VO}_{2}$ groups.

\begin{tabular}{lccc}
\hline & High $(n=53)$ & Average $(n=36)$ & $P$ value \\
\hline Glucose $(\mathrm{mg} / \mathrm{dL})$ & $87.7 \pm 6.8$ & $81.2 \pm 11.2$ & 0.200 \\
Cholesterol $(\mathrm{mg} / \mathrm{dL})$ & $173.3 \pm 20.6$ & $184.3 \pm 46.7$ & 0.000 \\
HDL-C $(\mathrm{mg} / \mathrm{dL})$ & $46.4 \pm 9.0$ & $34.1 \pm 7.1$ & 0.008 \\
LDL-C $(\mathrm{mg} / \mathrm{dL})$ & $106.1 \pm 16.3$ & $117.6 \pm 37.9$ & 0.000 \\
HDL/LDL & $0.45 \pm 0.13$ & $0.32 \pm 0.14$ & 0.006 \\
Triglyceride $(\mathrm{mg} / \mathrm{dL})$ & $102.6 \pm 45.7$ & $158.8 \pm 88.7$ & 0.025 \\
\hline
\end{tabular}

Values are in mean \pm SD. 


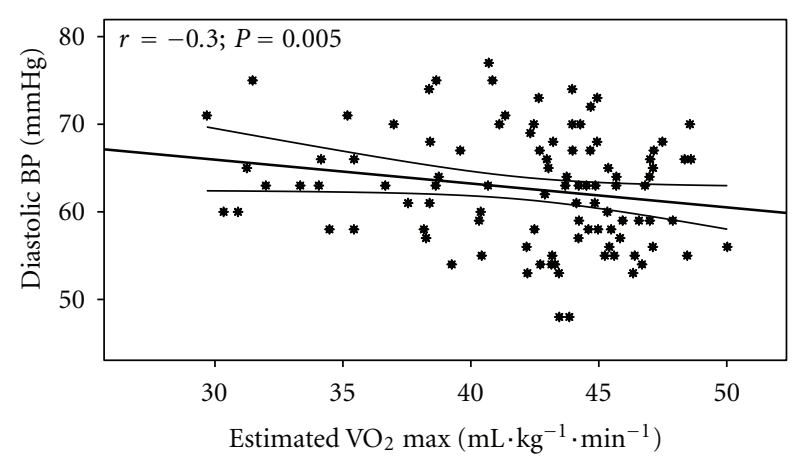

(a)

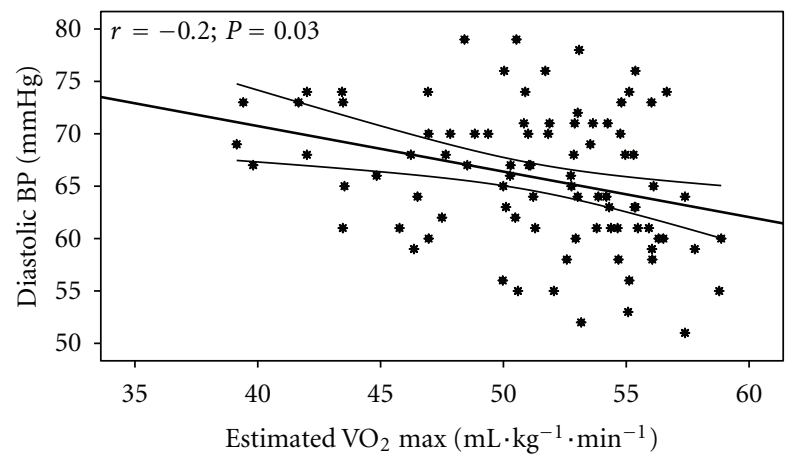

(b)

FIgURE 2: Estimated $\mathrm{VO}_{2}$ relationship with DBP in the females (a) $(r=-0.3 ; P=0.005)$ and males (b) $(r=-0.2 ; P=0.03)$.

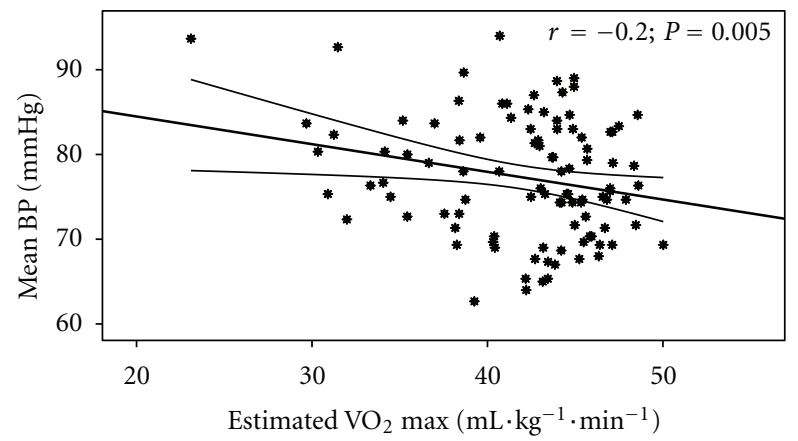

(a)

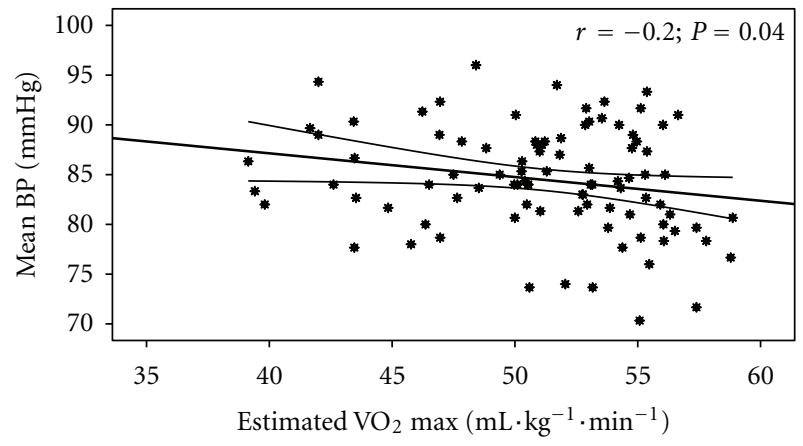

(b)

FIGURE 3: Estimated $\mathrm{VO}_{2}$ relationship with MAP in the females (a) $(r=-0.2 ; P=0.005)$ and males $(\mathrm{b})(r=-0.2 ; P=0.04)$.

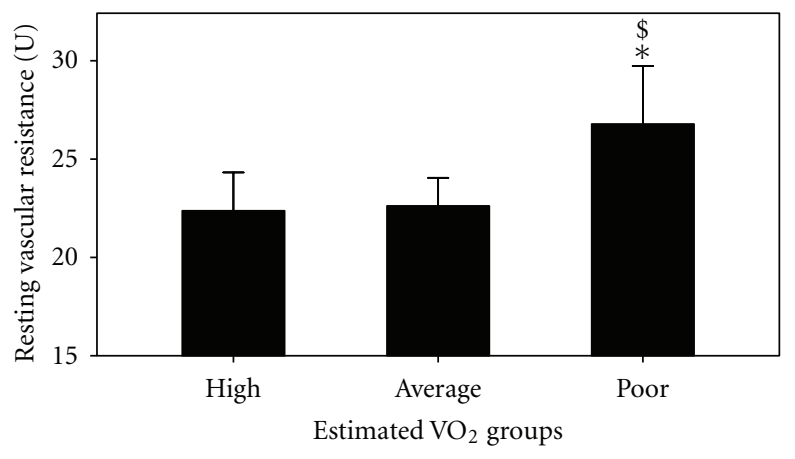

FIGURE 4: Resting vascular resistance in the poor, average, and high estimated $\mathrm{VO}_{2}$ max groups. ${ }^{*}: P<0.05$ versus average and ${ }^{\$}: P<$ 0.05 versus high groups.

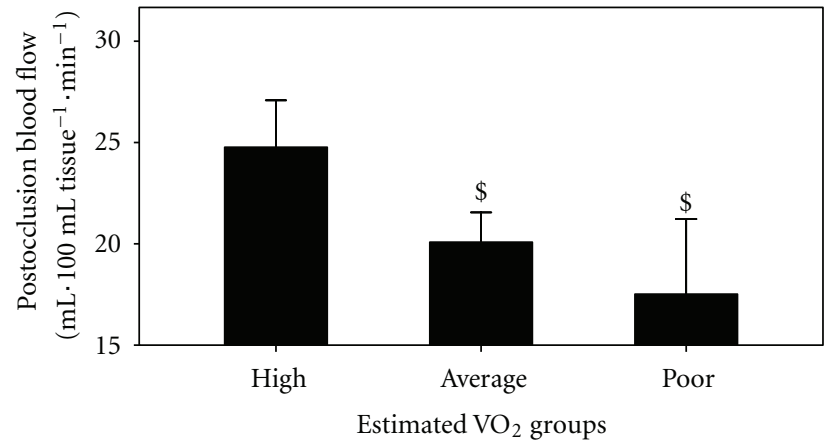

FIGURE 5: Postocclusion blood flow in the poor, average, and high estimated $\mathrm{VO}_{2}$ max groups. ${ }^{\$}=P<0.05$ versus high groups.

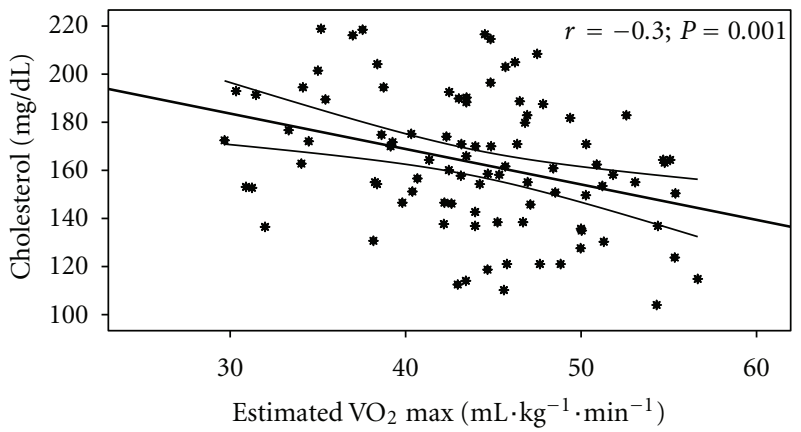

(a)

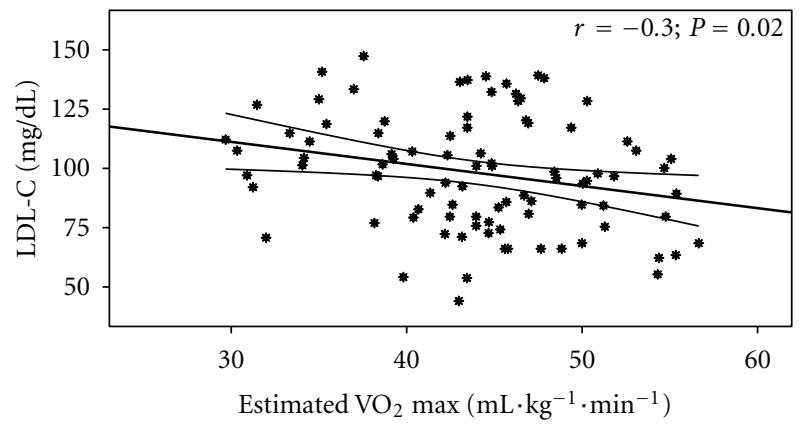

(b)

FIGURE 6: Estimated $\mathrm{VO}_{2}$ relationship with cholesterol (a) $(r=$ $-0.3 ; P=0.001)$ and LDL-C (b) $(r=-0.3 ; P=0.02)$. 


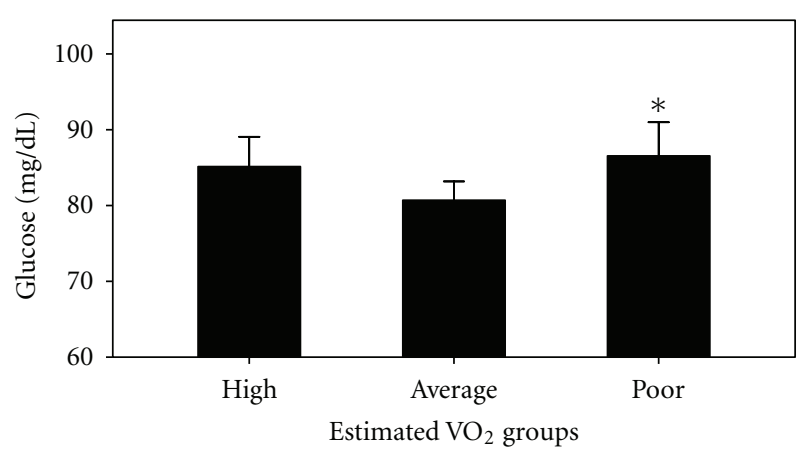

(a)

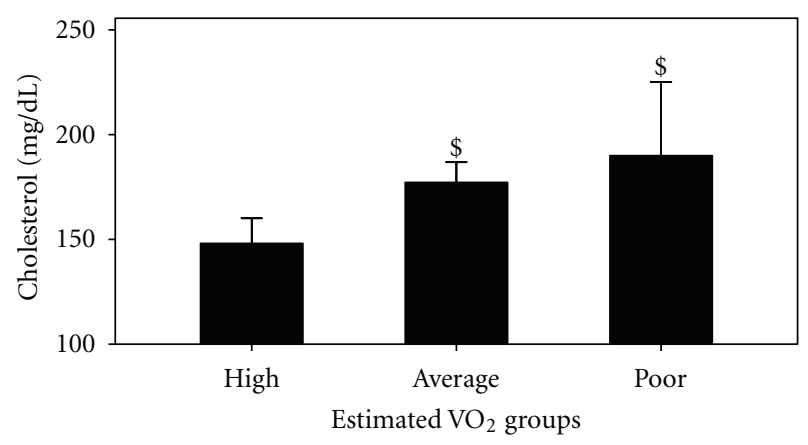

(b)

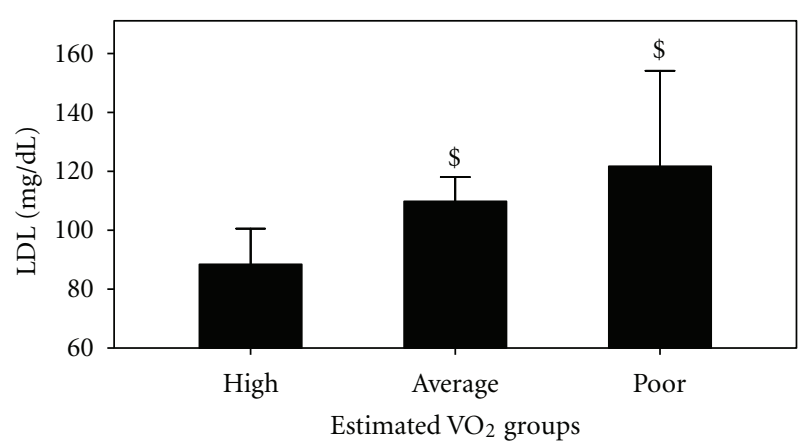

(c)

Figure 7: Blood glucose (a), cholesterol (b), and LDL-C (c) in the poor, average, and high estimated $\mathrm{VO}_{2}$ max groups. ${ }^{*}=P<0.05$ versus average group; ${ }^{\$}=P<0.05$ versus high group.

cholesterol, HDL-C, LDL-C, HDL/LDL, and triglyceride among the males were different $(P<0.05)$ between the high and average groups.

\section{Discussion}

Estimating $\mathrm{VO}_{2}$ max using the regression model was related to PF, body composition, circulatory, and blood glucose and lipid profile measures. Additionally, participants in the higher estimated $\mathrm{VO}_{2}$ max category were at lower risk profile. Obviously, the majority of these variables are established CVD risk factors and components of the metabolic syndrome. Therefore, these results further enhance the value of the regression model and thus can be used to estimate CVE in large-population settings.
Extensive efforts have recently been put forward to identify asymptomatic persons with or without CV risk factors to qualify for primary prevention using various diagnostic tools $[8,22-25]$. The diagnostic value of graded exercise testing (GXT) was recognized some time ago to record changes in physiological vitals (i.e., $\mathrm{HR}, \mathrm{BP}$, and respiratory rate) for patients with CVDs during maximal exertion [26, 27]. Finding these relationships is quite remarkable, especially that the participants were young and without CVDs or even risk factors. These results indicate that $\mathrm{NMVO}_{2}$ max seems to be useful to differentiate between individuals according to CVD risk factor profile and status of the metabolic syndrome. This is particularly important considering that previous ample evidences have suggested the possibility of using CVE testing in risk stratification for primary prevention in asymptomatic individuals $[6,7]$. The results of these studies suggest an independent prognostic and diagnostic values of maximal exercise capacity (i.e., CVE) regardless of age, gender, race, and health status [28].

In one of the earliest large-scale studies $(>50,000$ individuals) greater CVE was associated with 43 and 53\% lower all-cause mortality, as well as 47 and 70\% lower CV-related mortality in men and women, respectively [29, 30]. More recently, a meta-analysis for $>102,000$ individuals concluded a 13 and 15\% lower all-cause and CV-related mortalities, respectively, with every $1 \mathrm{MET}$ increase in CVE level. The authors further elaborated that a 1 MET increase in CVE level was comparable to a decrement $7 \mathrm{~cm}$ in waist circumference, $5 \mathrm{mmHg}$ in SBP, $1 \mathrm{mmol} / \mathrm{L}$ in triglyceride, $1 \mathrm{mmol} / \mathrm{L}$ in plasma glucose, and a $0.2 \mathrm{mmol} / \mathrm{L}$ increment in HDL-C [31].

Assessment of CVE is also valuable and widely used in quite few nonclinical settings for a variety of purposes. It can be utilized to predict future performance, is baseline for exercise prescription, is to evaluate the efficiency of exercise programs, and is helpful for positive motivation [32]. The relationships of estimated $\mathrm{VO}_{2}$ max with muscle mass, upper and lower body strength, HGS, and 6MWD measures, found herein, suggest that $\mathrm{NMVO}_{2}$ max can also be an acceptable indicator for PF confirming previous findings $[11-13,33]$. This is vital and indicates that $\mathrm{NMVO}_{2} \max$ might be a simple alternative tool to estimate CVE in young asymptomatic individuals for nonclinical purposes.

Forearm $\mathrm{BF}$ and $\mathrm{Vr}$ in the current study are associated with greater estimated $\mathrm{VO}_{2}$ max in young asymptomatic individuals confirming the importance of the arterial system for muscle $\mathrm{BF}$ to achieve greater $\mathrm{VO}_{2}$ and energy during maximum performance. Essentially, improved blood delivery to the working muscle results in reduced workload placed on all components of the CV system at any given intensity, including resting. This decrease in workload allows the CV system to function efficiently for longer period of time, delays fatigue, increases exercise tolerance, and is essential for healthy CV system [34, 35].

However, despite these compelling evidence confirming the clinical and nonclinical values of determining CVE [28-32, 36-39], it is largely underutilized, especially for CVD risk stratification. Rightfully so, one might argue that lengthy, inconvenient, and risky producers of maximal exertion during exercise testing might be the reason for not 
using CVE regularly. Alternatively, the current regression model is claimed to estimate CVE without the "burdens" associated with "conventional" exercise testing. The research group, who originally developed the equation, asserts that the model is relatively simple, low-cost, and low-risk estimate of CVE and could be used in clinical, nonclinical, and research settings. Additionally, the estimation of $\mathrm{VO}_{2} \max$ with the model can serve as a baseline for designing exercise prescriptions, monitoring adaptations to exercise, and measuring the success of exercise programming [10, $11,13]$. One slight deviation from the original model is estimating CVE in the current study with the IPAQ, which classifies the participants into 3 versus 5 levels used in the original equation $[10,13]$. We think this modification can make the model more versatile and acceptable in wider-range settings.

Needless to say, repeatedly challenging the body with exercise results in adaptations of various body systems to assure proper energy production during subsequent physical exertion. Habitual exercise training is associated with increased CV endurance, HGS, and upper and lower body strengths. Similarly, overwhelming data demonstrate that regular participation in exercise training results in changes in body composition measures. Favorable alterations in weight, abdominal obesity, percent body fat, BMI, and fat-free mass have been observed even after low-intensity exercise (i.e., walking). Though the mechanism(s) for these adaptations are not entirely known, exercise seems to increase metabolic rate thereby energy expenditure, even during resting [40$44]$. Changes in blood glucose and lipid profile are also well established following exercise training, especially aerobic. Blood glucose, cholesterol, LDL-C, and triglyceride are lower whereas HDL-C is greater in physically active individuals [40-44]. Regular exercise also improves muscle blood flow and $\mathrm{VO}_{2}$ to meet the metabolic demands in subsequent exercise sessions. The improved blood flow has been attributed to endothelium-dependent and -independent structural and functional changes. These changes include enhanced endothelial [45] and metabolically [46] mediated vasodilatations, arterial smooth muscle responsiveness [47], and reduced norepinephrine [48] and endothlin1-mediated arterial constrictions $[49,50]$. Nonetheless, since the CV system is a continuum, the improvements in the capabilities of various components directly interact with each other to enhance $\mathrm{O}_{2}$ delivery to the working muscles $[35,51,52]$. Alterations in blood and stroke volumes, cardiac dimensions and output, and neurohormonal balance have also been observed after aerobic exercise $[53,54]$.

\section{Conclusion}

Estimation of cardiovascular endurance was related to CVD risk factors and components of the metabolic syndrome including measures of obesity, PF, circulatory, and blood glucose and lipid profile. Thus, the data indicate that the $\mathrm{NM}$, evaluated herein, can be potentially used as an indirect measure of $\mathrm{VO}_{2}$ max to screen for CVD risk factors. These results further enhance the scientific value of the NM to be used more in clinical and nonclinical settings. Finally, the findings confirm that CVE is useful for weight control, physical capacity, CV risk factor management and general CV health.

\section{Acknowledgment}

The research project was funded in full by the Deanship of Scientific Research at the Jordan University of Science and Technology with Grant nos.: MA200/2007 and MA119/2010.

\section{References}

[1] E. Braunwald, "Shattuck lecture cardiovascular medicine at the turn of the millennium: triumphs, concerns, and opportunities," New England Journal of Medicine, vol. 337, no. 19, pp. 1360-1369, 1997.

[2] S. E. Brien, I. Janssen, and P. T. Katzmarzyk, "Cardiorespiratory fitness and metabolic syndrome: US National Health and Nutrition Examination Survey 1999-2002," Applied Physiology, Nutrition and Metabolism, vol. 32, no. 1, pp. 143-147, 2007.

[3] D. C. Lee, E. G. Artero, X. Sui, and S. N. Blair, "Mortality trends in the general population: the importance of cardiorespiratory fitness," Journal of Psychopharmacology, vol. 24, supplement 4, pp. 27-35, 2010.

[4] P. S. Yusuf, S. Hawken, S. Ônpuu et al., "Effect of potentially modifiable risk factors associated with myocardial infarction in 52 countries (the INTERHEART study): case-control study," The Lancet, vol. 364, no. 9438, pp. 937-952, 2004.

[5] M. J. O'Donnell, X. Denis, L. Liu et al., "Risk factors for ischaemic and intracerebral haemorrhagic stroke in 22 countries (the INTERSTROKE study): a case-control study," The Lancet, vol. 376, no. 9735, pp. 112-123, 2010.

[6] G. J. Balady, M. G. Larson, R. S. Vasan, E. P. Leip, C. J. O'Donnell, and D. Levy, "Usefulness of exercise testing in the prediction of coronary disease risk among asymptomatic persons as a function of the Framingham risk score," Circulation, vol. 110, no. 14, pp. 1920-1925, 2004.

[7] A. Fowler-Brown, M. Pignone, M. Pletcher, J. A. Tice, S. F. Sutton, and K. N. Lohr, "Exercise tolerance testing to screen for coronary heart disease: a systematic review for the technical support for the U.S. Preventive Services Task Force," Annals of Internal Medicine, vol. 140, no. 7, pp. W9-24, 2004.

[8] L. Sharples, V. Hughes, A. Crean et al., "Cost-effectiveness of functional cardiac testing in the diagnosis and management of coronary artery disease: a randomised controlled trial. The CECaT trial," Health Technology Assessment, vol. 11, no. 49, pp. iii-iv-ix-115, 2007.

[9] L. Pilote, F. Pashkow, J. D. Thomas et al., "Clinical yield and cost of exercise treadmill testing to screen for coronary artery disease in asymptomatic adults," American Journal of Cardiology, vol. 81, no. 2, pp. 219-224, 1998.

[10] A. S. Jackson, S. N. Blair, M. T. Mahar, L. T. Wier, R. M. Ross, and J. E. Stuteville, "Prediction of functional aerobic capacity without exercise testing," Medicine and Science in Sports and Exercise, vol. 22, no. 6, pp. 863-870, 1990.

[11] H. N. Williford, M. Scharff-Olson, N. Wang, D. L. Blessing, F. H. Smith, and W. J. Duey, "Cross-validation of non-exercise predictions of $\mathrm{VO}(2 \mathrm{peak})$ in women," Medicine and Science in Sports and Exercise, vol. 28, no. 7, pp. 926-930, 1996. 
[12] E. L. Mailey, S. M. White, T. R. Wojcicki, A. N. Szabo, A. F. Kramer, and E. McAuley, "Construct validation of a nonexercise measure of cardiorespiratory fitness in older adults," BMC Public Health, vol. 10, article 59, 2010.

[13] R. Jurca, A. S. Jackson, M. J. LaMonte et al., "Assessing cardiorespiratory fitness without performing exercise testing," American Journal of Preventive Medicine, vol. 29, no. 3, pp. 185-193, 2005.

[14] A. Ghayoumi, V. Raxwal, S. Cho, J. Myers, S. Chun, and V. F. Froelicher, "Prognostic value of exercise tests in male veterans with chronic coronary artery disease," Journal of Cardiopulmonary Rehabilitation, vol. 22, no. 6, pp. 399-407, 2002.

[15] P. Sarto, L. Merlo, P. Astolfo, M. Sarto, L. Bedin, and D. Noventa, "Comprehensive therapeutic program for cardiovascular patients: role of a sports medicine unit in collaboration with local gymnasiums," Journal of Cardiovascular Medicine, vol. 10, no. 1, pp. 27-33, 2009.

[16] D. O. Fedder, C. E. Koro, and G. J. L'Italien, "New National Cholesterol Education Program III guidelines for primary prevention lipid-lowering drug therapy: projected impact on the size, sex, and age distribution of the treatment-eligible population," Circulation, vol. 105, no. 2, pp. 152-156, 2002.

[17] G. M. Adams and W. C. Beam, Exercise Physiology: Laboratory Manual, McGraw-Hill, Boston, Mass, USA, 2008.

[18] N. D. Harada, V. Chiu, and A. L. Stewart, "Mobility-related function in older adults: assessment with a 6-minute walk test," Archives of Physical Medicine and Rehabilitation, vol. 80, no. 7, pp. 837-841, 1999.

[19] M. A. Alomari, A. Solomito, R. Reyes, S. M. Khalil, R. H. Wood, and M. A. Welsch, "Measurements of vascular function using strain-gauge plethysmography: technical considerations, standardization, and physiological findings," American Journal of Physiology, vol. 286, no. 1, pp. H99-H107, 2004.

[20] M. Y. Gharibeh, G. M. Al Tawallbeh, M. M. Abboud, A. Radaideh, A. A. Alhader, and O. F. Khabour, "Correlation of plasma resistin with obesity and insulin resistance in type 2 diabetic patients," Diabetes and Metabolism, vol. 36, no. 6, pp. 443-449, 2010.

[21] M. A. Alomari, E. F. Keewan, R. Qhatan et al., "Blood pressure and circulatory relationships with physical activity level in young normotensive individuals: IPAQ validity and reliability considerations," Clinical and Experimental Hypertension, vol. 33, no. 5, pp. 345-353, 2011.

[22] D. A. Duprez and J. N. Cohn, "Identifying early cardiovascular disease to target candidates for treatment," Journal of Clinical Hypertension, vol. 10, no. 3, pp. 226-231, 2008.

[23] T. R. Church, M. Hodges, J. J. Bailey, and S. J. Mongin, "Risk stratification applied to CAST registry data: combining 9 predictors," Journal of Electrocardiology, vol. 35, pp. 117-122, 2002.

[24] P. Greenland, S. C. Smith Jr., and S. M. Grundy, "Improving coronary heart disease risk assessment in asymptomatic people: role of traditional risk factors and noninvasive cardiovascular tests," Circulation, vol. 104, no. 15, pp. 1863-1867, 2001.

[25] R. Arena, J. Myers, J. Abella et al., "Cardiopulmonary exercise testing is equally prognostic in young, middle-aged and older individuals diagnosed with heart failure," International Journal of Cardiology, vol. 151, no. 3, pp. 278-283, 2011.

[26] C. B. Chapman, "Edward smith (?1818-1874) physiologist, human ecologist, reformer," Journal of the History of Medicine and Allied Sciences, vol. 22, no. 1, pp. 1-26, 1967.
[27] K. J. Carpenter, "Edward smith (1819-1874)," Journal of Nutrition, vol. 121, no. 10, pp. 1515-1521, 1991.

[28] M. Gulati, D. K. Pandey, M. F. Arnsdorf et al., "Exercise capacity and the risk of death in women: the St. James Women Take Heart Project," Circulation, vol. 108, no. 13, pp. 15541559, 2003.

[29] M. L. Pollock, R. L. Bohannon, and K. H. Cooper, "A comparative analysis of four protocols for maximal treadmill stress testing," American Heart Journal, vol. 92, no. 1, pp. 3946, 1976.

[30] M. L. Pollock, C. Foster, and D. Schmidt, "Comparative analysis of physiologic responses to three different maximal graded exercise test protocols in healthy women," American Heart Journal, vol. 103, no. 3, pp. 363-373, 1982.

[31] S. Kodama, K. Saito, S. Tanaka et al., "Cardiorespiratory fitness as a quantitative predictor of all-cause mortality and cardiovascular events in healthy men and women: a metaanalysis," Journal of the American Medical Association, vol. 301, no. 19, pp. 2024-2035, 2009.

[32] M. H. Whaley, P. H. Brubaker, R. M. Otto, and L. E. Armstrong, ACSM's Guidelines for Exercise Testing and Prescription, Lippincott Williams \& Wilkins, Philadelphia, Pa, USA, 2006.

[33] H. M. Al, "Prevalence and trends in obesity among school boys in Central Saudi Arabia between 1988 and 2005," Saudi Medical Journal, vol. 28, no. 10, pp. 1569-1574, 2007.

[34] B. Saltin, "Physiological adaptation to physical conditioning. Old problems revisited," Acta Medica Scandinavica, vol. 220, no. 711, pp. 11-24, 1986.

[35] J. P. Clausen, "Effect of physical training on cardiovascular adjustments to exercise in man," Physiological Reviews, vol. 57, no. 4, pp. 779-815, 1977.

[36] M. R. Carnethon, M. Gulati, and P. Greenland, "Prevalence and cardiovascular disease correlates of low cardiorespiratory fitness in adolescents and adults," Journal of the American Medical Association, vol. 294, no. 23, pp. 2981-2988, 2005.

[37] N. L. Chase, X. Sui, D. C. Lee, and S. N. Blair, "The association of cardiorespiratory fitness and physical activity with incidence of hypertension in men," American Journal of Hypertension, vol. 22, no. 4, pp. 417-424, 2009.

[38] D. C. Lee, X. Sui, T. S. Church, I. M. Lee, and S. N. Blair, "Associations of cardiorespiratory fitness and obesity with risks of impaired fasting glucose and type 2 diabetes in men," Diabetes Care, vol. 32, no. 2, pp. 257-262, 2009.

[39] S. N. Blair, H. W. Kohl, C. E. Barlow, R. S. Paffenbarger Jr., L. W. Gibbons, and C. A. Macera, "Changes in physical fitness and all-cause mortality: a prospective study of healthy and unhealthy men," Journal of the American Medical Association, vol. 273, no. 14, pp. 1093-1098, 1995.

[40] R. P. Pangrazi, A. Beighle, and D. Pangrazi, Promoting Physical Activity \& Health in the Classroom, Benjamin Cummings, San Francisco, Calif, USA, 2009.

[41] A. E. Hardman and D. J. Stensel, Physical Activity and Health: The Evidence Explained, Routledge, London, UK, 2009.

[42] M. E. Nelson, W. J. Rejeski, S. N. Blair et al., "Physical activity and public health in older adults: recommendation from the American College of Sports Medicine and the American Heart Association," Circulation, vol. 116, no. 9, pp. 1094-1105, 2007.

[43] W. L. Haskell, I. M. Lee, R. R. Pate et al., "Physical activity and public health: updated recommendation for adults from the American College of Sports Medicine and the American Heart Association," Circulation, vol. 116, no. 9, pp. 1081-1093, 2007.

[44] C. Bouchard, S. N. Blair, and W. L. Haskell, Physical Activity and Health, Human Kinetics, Champaign, Ill, USA, 2007. 
[45] P. Clarkson, H. E. Montgomery, M. J. Mullen et al., "Exercise training enhances endothelial function in young men," Journal of the American College of Cardiology, vol. 33, no. 5, pp. 13791385, 1999.

[46] M. D. Delp and M. H. Laughlin, "Regulation of skeletal muscle perfusion during exercise," Acta Physiologica Scandinavica, vol. 162, no. 3, pp. 411-419, 1998.

[47] D. J. Green, J. G. O’Driscoll, B. A. Blanksby, and R. R. Taylor, "Effect of casting on forearm resistance vessels in young men," Medicine and Science in Sports and Exercise, vol. 29, no. 10, pp. 1325-1331, 1997.

[48] D. L. Wiegman, P. D. Harris, I. G. Joshua, and F. N. Miller, "Decreased vascular sensitivity to norepinephrine following exercise training," Journal of Applied Physiology Respiratory Environmental and Exercise Physiology, vol. 51, no. 2, pp. 282287, 1981.

[49] A. W. Jones, L. J. Rubin, and L. Magliola, "Endothelin1 sensitivity of porcine coronary arteries is reduced by exercise training and is gender dependent," Journal of Applied Physiology, vol. 87, no. 3, pp. 1172-1177, 1999.

[50] S. Maeda, T. Miyauchi, T. Kakiyama et al., "Effects of exercise training of 8 weeks and detraining on plasma levels of endothelium-derived factors, endothelin-1 and nitric oxide, in healthy young humans," Life Sciences, vol. 69, no. 9, pp. 10051016, 2001.

[51] B. Saltin, K. Nazar, and D. L. Costill, "The nature of the training response; peripheral and central adaptations to one legged exercise," Acta Physiologica Scandinavica, vol. 96, no. 3, pp. 289-305, 1976.

[52] M. D. Delp, "Differential effects of training on the control of skeletal muscle perfusion," Medicine and Science in Sports and Exercise, vol. 30, no. 3, pp. 361-374, 1998.

[53] B. Saltin, "Hemodynamic adaptations to exercise," American Journal of Cardiology, vol. 55, no. 10, 1985.

[54] J. Praetorius Clausen, "Circulatory adjustments to dynamic exercise and effect of physical training in normal subjects and in patients with coronary artery disease," Progress in Cardiovascular Diseases, vol. 18, no. 6, pp. 459-495, 1976. 


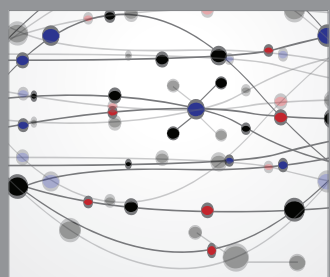

The Scientific World Journal
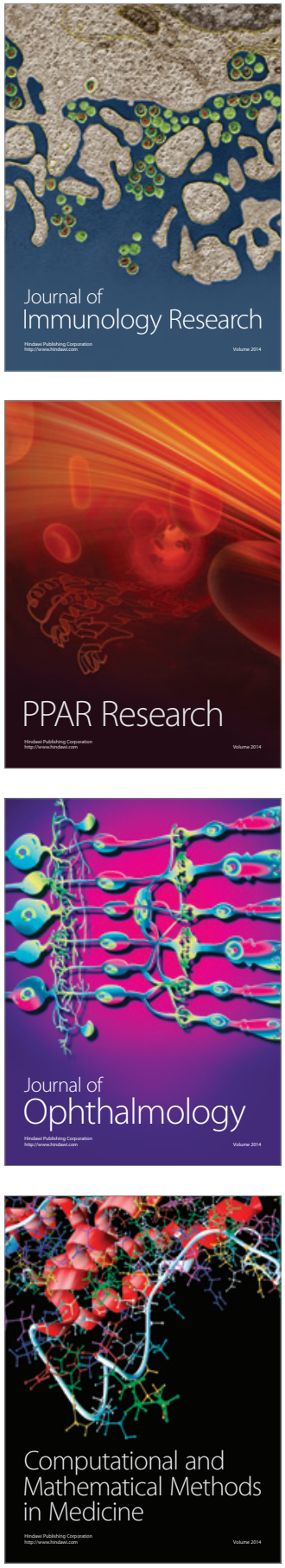

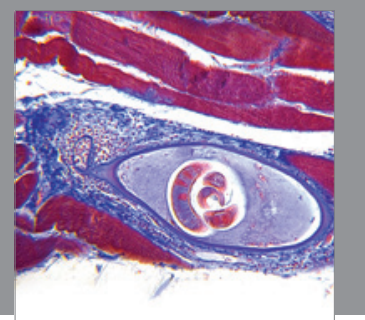

Gastroenterology

Research and Practice
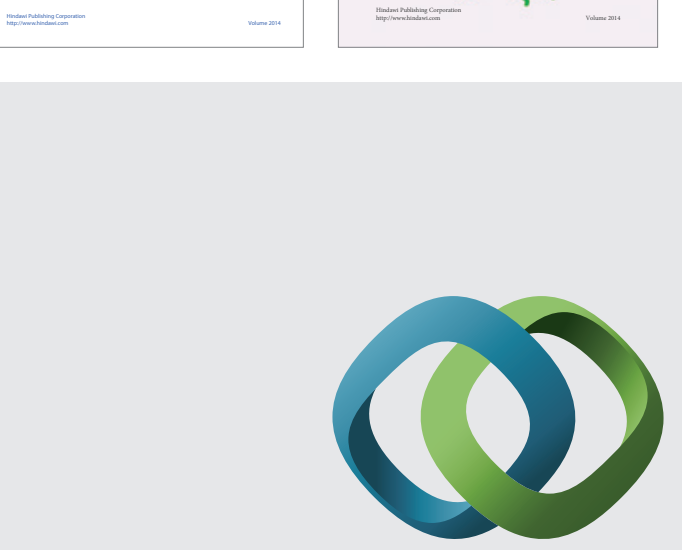

\section{Hindawi}

Submit your manuscripts at

http://www.hindawi.com
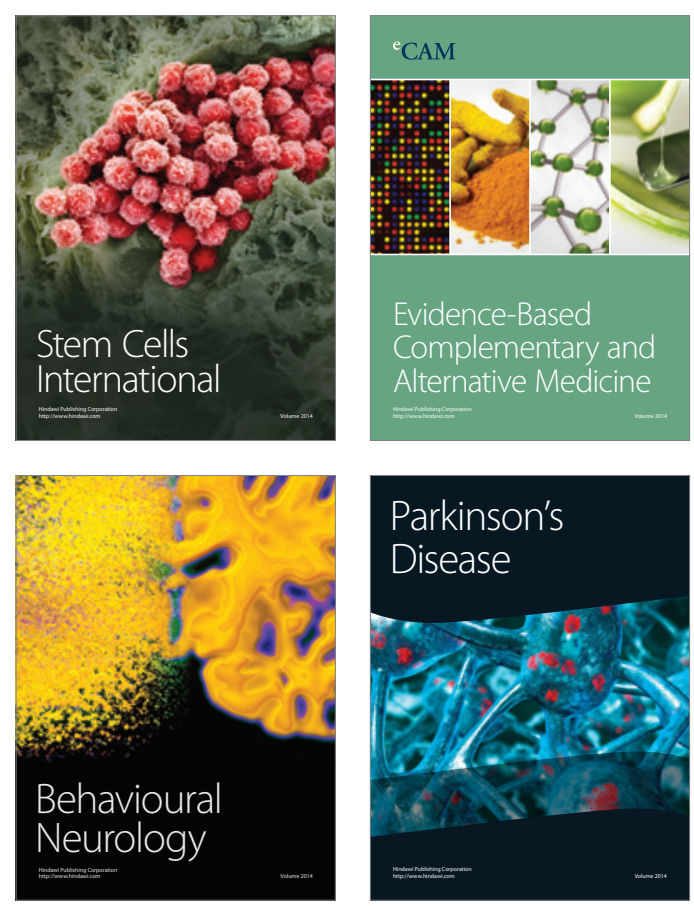

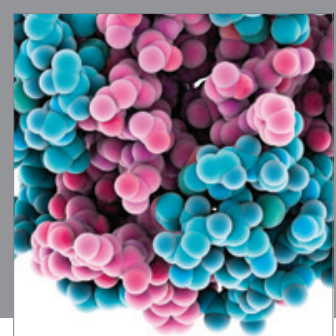

Journal of
Diabetes Research

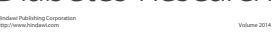

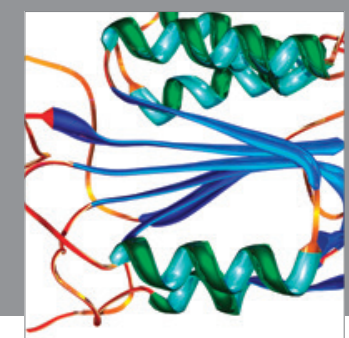

Disease Markers
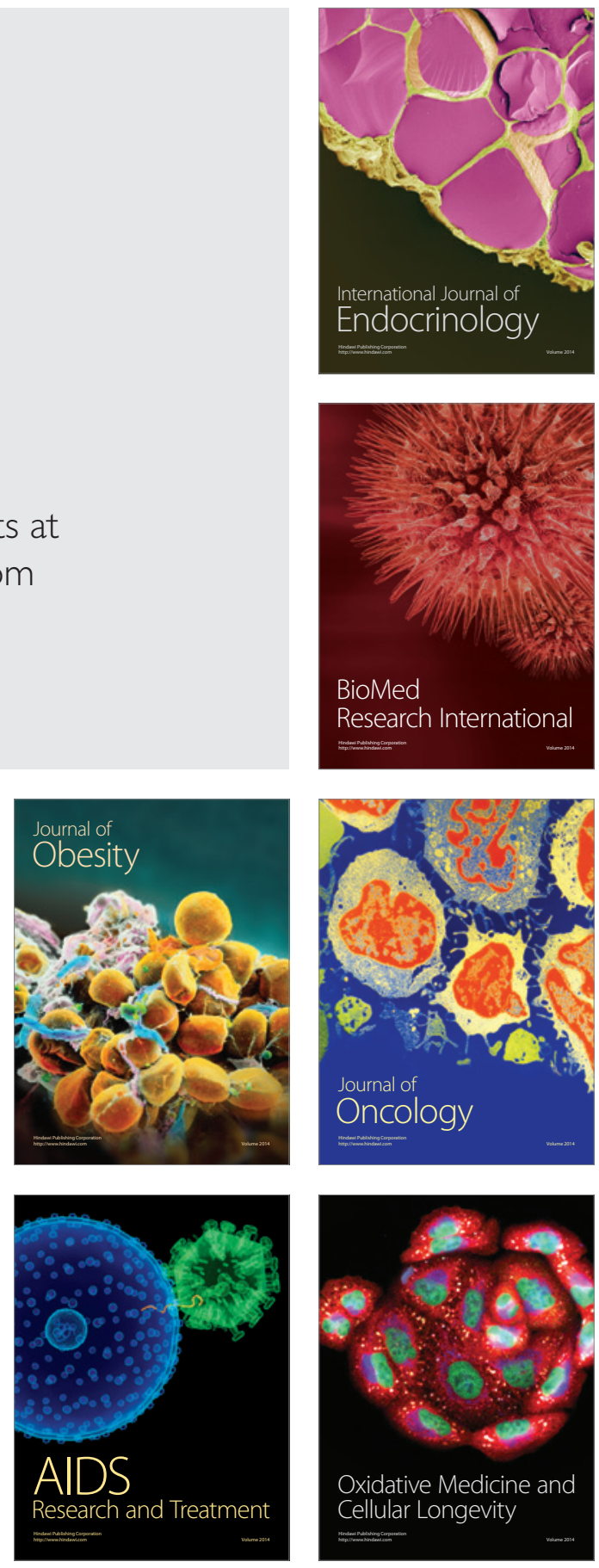